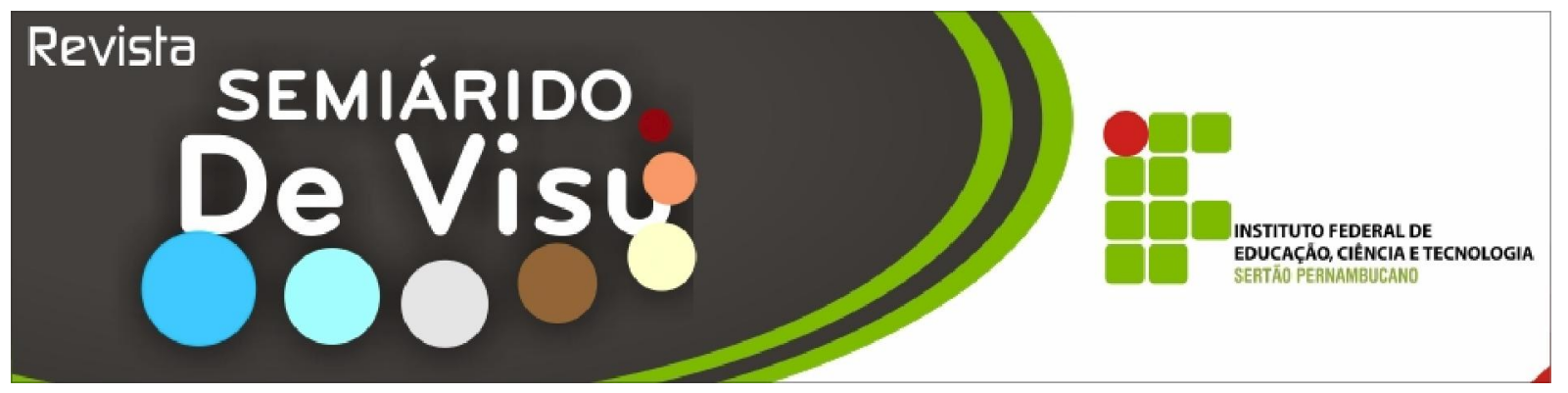

\title{
Avaliação da qualidade de linguiça de Tilápia do Nilo (Oreochromis niloticus)
}

\author{
Luciana Façanha Marques ${ }^{1}$, Jaderlany Souza Nunes ${ }^{2}$, Deise Souza Castro ${ }^{2}$, Lilian Karla Araújo ${ }^{2}$, \\ Maria Ludimila Silva Sales ${ }^{2}$
}

1Professora do IF Sertão Pernambucano - Campus Salgueiro-PE BR 232 km 509 Zona Rural (87) 3421-0050

luciana.marques@ifsertao-pe.edu.br

2Tecnóloga em Alimentos - Faculdade de Tecnologia CENTEC - FATEC CARIRI Rua Amália Xavier, s/n Juazeiro do Norte-CE (88) 3566-4041 jade_nunes@hotmail.com

RESUMO: A diversificação na linha de processamento do pescado pode contribuir com o aumento do consumo. Baseado neste fator objetivou-se produzir linguiça de tilápia com duas formulações diferentes fazendo-se também análises sensoriais, físico-químicas e da qualidade higiênico-sanitárias das mesmas. Realizando-se então a análise sensorial com 30 provadores não treinados, não detectando diferenças significativas $(\mathrm{p}<0,05)$ quanto aos atributos avaliados, sendo que os resultados revelaram a preferência pela formulação com maior teor de lipídios. As análises físico-químicas das amostras foram realizadas segundo métodos analíticos do Instituto Adolfo Lutz. Na determinação a amostra CB apresentou os seguintes resultados: pH: 6,11, Acidez: 0,1168\%, Proteína: 13,8267\%, Umidade: 78,0363\%, Cinzas: 1,8284\%, Lipídios: 13,7442\% e a amostra SB mostrou pH: 5,81, Acidez: 0,0922\%, Proteína: 10,4862\%, Umidade: $82,4350 \%$, Cinzas: 2,1263\%, Lipídios: 14,7435\%. As análises microbiológicas foram realizadas de acordo com a metodologia recomendada pela APHA (2000), dentre as quais: número mais provável de coliformes fecais, número mais provável de coliformes totais, contagem de Staphylococcus Aureus, presença ou ausência de Salmonella. Mostrando-se dentro dos padrões indicados pela legislação.

Palavras- chave: Pescado, aceitação, lipídios, proteínas.

\section{Quality assessment sausage Tilapia Nile (Oreochromis niloticus)}

\begin{abstract}
Diversification in the fish processing line can contribute to the increased consumption. Based on this factor aimed to produce tilapia sausage with two different formulations, is also doing sensory analysis, physicochemical and microbiological quality of them. Then carrying out the sensory analysis of 30 non-trained panelists detected no significant differences $(\mathrm{p}<0.05)$ among attributes evaluated, and the results revealed a preference for the formulation with higher content of lipids. The physical-chemical analysis of samples were performed according to analytical methods of the Instituto Adolfo Lutz. In determining the sample CB showed the following results: $\mathrm{pH}$ : 6.11 , acidity: $0.1168 \%$, Protein: $13.8267 \%$, Moisture: $78.0363 \%$, Ash: $1.8284 \%$ Lipids: $13.7442 \%$ SB and the sample showed pH: 5.81, acidity: $0.0922 \%$, Protein: $10.4862 \%$, Moisture: $82.4350 \%$, Ash: $2.1263 \%$ Lipids: $14.7435 \%$. Microbiological tests were performed according to the methodology recommended by APHA (2000), including: most probable number of fecal coliform most probable number of coliforms, Staphylococcus aureus, the presence or absence of Salmonella. Showing up within the standards specified by law.
\end{abstract}

Key words: Fish, acceptance, lipids, proteins. 
Luciana Façanha Marques et al.

\section{Introdução}

tualmente, a indústria de pesca
tem crescido consideravelmente
tanto pela demanda do consumidor, como pelas inovações tecnológicas pelas quais a indústria está passando, porém é necessário acompanhar estas inovações com a melhoria nos programas de inspeção de qualidade e de processamento. $\mathrm{O}$ pescado por apresentar algumas características peculiares inerentes ao modo de captura, sua biologia e tipos de processamento, torna-se diferente de outros alimentos de origem animal requerendo para isto um processamento apropriado (LEITÃO, 1994).

Segundo Sales et al. (1988), dos alimentos cárneos, o pescado é o que se decompõe mais rapidamente, isto devido sua constituição pobre em tecido conjuntivo como também suas características especiais do tecido muscular que tem o $\mathrm{pH}$ aumentado após a morte. Por ser rico em nutrientes, principalmente proteínas, e muito susceptível ao ataque e/ou desenvolvimento microbiano, além de poder sofrer alterações de natureza física ou química, que irão refletir em suas características organolépticas podendo além de acarretar perda do produto ocasionar riscos a saúde dos consumidores (BRASIL, 1976).

A carne do pescado é um alimento de fácil digestão, fonte de proteínas, minerais, principalmente cálcio e fósforo, vitaminas lipossolúveis A e D e hidrossolúveis do complexo B, além de ser fonte de ácidos graxos monoinsaturados e poliinsaturados, entre eles os ômegas-3 (KIRSCHNIK, 2007).

As proteínas da carne do pescado apresentam na sua composição todos os aminoácidos essenciais para a dieta humana, alta digestibilidade devido ao alto teor de lisina (aminoácido presente em baixos teores na dieta do brasileiro) e, portanto, alto valor biológico, superior ao de outras fontes animais como ovos, leite e carne bovina. A fração lipídica dos pescados, além de fonte energética, apresenta cerca de $70 \%$ de ácidos graxos insaturados. Os ácidos graxos da família $\alpha-3$ são essenciais para o desenvolvimento das células nervosas durante a formação do feto e sua carência durante a gestação acarreta em tragédia para a vida extrauterina futura (WEBER, 2007).

Dentre as espécies de pescado cultivadas no país, a Tilápia do Nilo (Oreochromis niloticus) é a de maior produção por apresentar um crescimento mais rápido e reprodução mais tardia que permite maior tamanho antes da primeira reprodução; além de apresentar maior preferência do consumidor devido um menor número de espinhas no seu esqueleto. Segundo Vaz (2005) esta espécie representa o segundo grupo de maior importância na aqüicultura mundial.

Mesmo o pescado apresentando grandes propriedades e o país tendo grande potencial que favorece atividade da piscicultura, o consumo do pescado no Brasil ainda é baixo, segundo a FAO o consumo de pescado no Brasil em 2004 foi de 5,6 Kg/habitantes/ano, bem abaixo do índice apresentado por outros países que não apresentam condições propícias para produção destes animais.

Minozzo et al. (2002), realizaram pesquisa de mercado na cidade de Toledo/Paraná, demonstraram que $88 \%$ dos entrevistados responderam que consomem peixe, sendo a espécie mais consumida a tilápia com $58 \%$ da preferência.

Objetivou-se produzir linguiça de tilápia com duas formulações diferente fazendo análises sensoriais, físico-químicas e da qualidade higiênico-sanitárias das mesmas.

\section{Material e métodos}

\section{Obtenção da matéria prima}

$O$ filé de tilápia do Nilo congelado foi obtido de um supermercado local, onde se encontrava sobre refrigeração e em boas condições de consumo. A matéria prima foi colocada em caixas térmica para o controle da temperatura e transportada para o laboratório de processamento de Alimentos da Faculdade de Tecnologia CENTEC - FATEC CARIRI.

\section{Processamento}

Foram realizadas duas formulações que podem ser visualizadas nas tabelas 1 e 2 abaixo. 
Luciana Façanha Marques et al.

Tabela 1: Formulação da linguiça de tilápia do Nilo sem bacon

\begin{tabular}{l|c|c}
\hline \multicolumn{1}{c|}{ COMPONENTE } & $\mathbf{\%}$ & FUNÇÃO NO PRODUTO \\
\hline Peixe & 82 & Produto base \\
\hline Água & 16 & Textura (maciez) \\
\hline Sal Refinado & 1 & "Flavor", Conservante \\
\hline Sal de Cura & 0,26 & Conservante \\
\hline Condimento Califórnia & 0,26 & "Flavor" \\
\hline Alho & 0,09 & "Flavor" \\
\hline Pimenta & 0,09 & "Flavor" \\
\hline
\end{tabular}

Tabela 2: Formulação de linguiça de tilápia do Nilo com bacon

\begin{tabular}{l|c|c}
\hline \multicolumn{1}{c|}{ COMPONENTE } & \% & FUNÇÃO NO PRODUTO \\
\hline Peixe & 76 & Produto base \\
\hline Água & 15 & Textura (maciez) \\
\hline Sal Refinado & 0,9 & "Flavor", Conservante \\
\hline Sal de Cura & 0,22 & Conservante \\
\hline Condimento Califórnia & 0,22 & "Flavor" \\
\hline Alho & 0,08 & "Flavor" \\
\hline Pimenta & 0,08 & "Flavor" \\
\hline Bacon & 7 & Textura (maciez) \\
\hline
\end{tabular}

O processamento da linguiça foi feito de acordo com o fluxograma descrito na figura 01 .

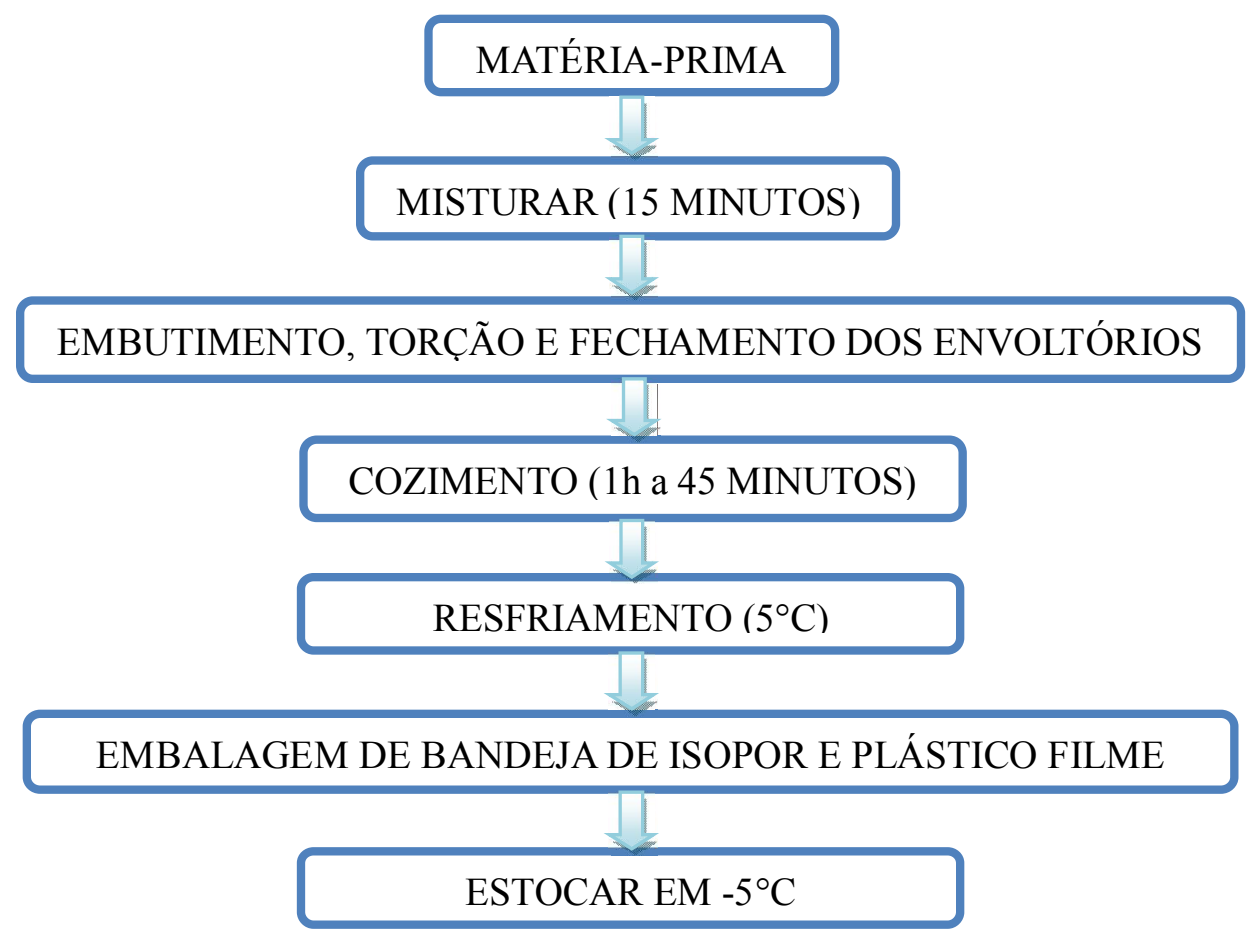

Figura 1 - Fluxograma do processamento da linguiça de tilápia do Nilo 
Luciana Façanha Marques et al.

Os filés foram descongelados e moídos em um triturador caseiro; sofrendo em seguida a mistura e homogeneização com os demais ingredientes na porção apresentada nas tabelas 1 e 2, diferindo apenas dos ingredientes a adição de banco em uma das formulações; a massa foi embutida em tripas naturais e, posteriormente, armazenada em bandejas de isopor, recobertos por plástico filme, como nos mostra a figura 01. Finalmente, o produto obtido foi mantido em temperatura de congelamento.

\section{Analise sensorial}

O teste de aceitabilidade foi realizado em relação aos atributos aparência global, aroma, sabor e textura (DUTCOSKY, 1996). Trinta provadores avaliaram o quanto gostaram ou desgostaram do produto, utilizando escala hedônica estruturada de 9 pontos, indo de 1 (desgostei muitíssimo) a 9 (gostei muitíssimo). Foi realizado teste de atitude de intenção de compra (escala de categoria bipolar de 5 pontos).

\section{Análises Físico-químicas}

A caracterização físico-química do produto final consistiu na determinação do teor de umidade, $\mathrm{pH}$, lipídios totais, proteínas,resíduos minerais fixos e acidez, de acordo com os métodos analíticos do Instituto Adolfo Lutz (2004).

\section{Análise microbiológica}

As análises microbiológicas foram realizadas no laboratório de microbiologia de Alimentos da Faculdade de tecnologia CENTEC - FATEC CARIRI, em acordo com a metodologia recomendada pela APHA (2000), dentre as quais: número mais provável de coliformes fecais, número mais provável de coliformes totais, contagem de Staphylococcus Aureus, presença ou ausência de Salmonella.

\section{Resultados e discussão}

Análise sensorial
Um dos fatores críticos para o
desenvolvimento de novos produtos
alimentícios é a aceitabilidade por parte dos
consumidores (CORREIA et al., 2001). Como
a maioria das respostas do teste empregado
situou-se entre as três últimas categorias da
escala de atitudes, correspondendo "gostei
extremamente" até "gostei moderadamente", ao
se analisar os resultados (Figura 2), pode-se
considerar que os produtos obtiveram boa
aceitação para os atributos avaliados (cor,
aroma, sabor, aparência e textura). Resultado
semelhante encontrado por Correia et al,2001,
a avaliação positiva foi sentida sobretudo para a
formulação com bacon, que alcançou 7,2 das
respostas neste patamar, seguido de 6,9 , para a
formulação sem bacon. Portanto a aceitação das
formulações não diferiram entre si
estatisticamente.

\section{Análise sensorial}

críticos para o desenvolvimento de novos produtos alimentícios é a aceitabilidade por parte dos consumidores (CORREIA et al., 2001). Como a maioria das respostas do teste empregado situou-se entre as três últimas categorias da escala de atitudes, correspondendo "gostei nte", ao pode-se considerar que os produtos obtiveram boa aceitação para os atributos avaliados (cor, aroma, sabor, aparência e textura). Resultado semelhante encontrado por Correia et al,2001, a avaliação positiva foi sentida sobretudo para a formulação com bacon, que alcançou 7,2 das respostas neste patamar, seguido de 6,9, para a formulação sem bacon. Portanto a aceitação das estatisticamente. 
Luciana Façanha Marques et al.

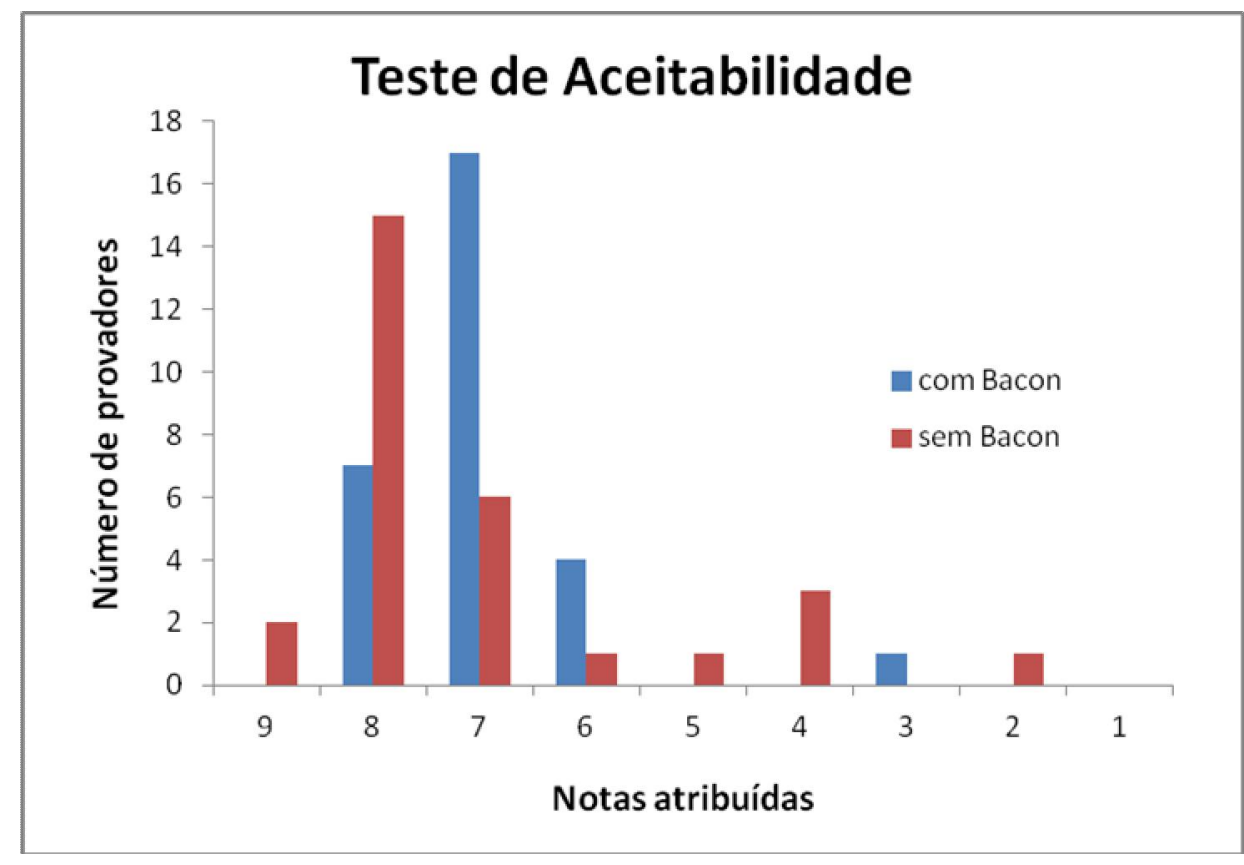

Figura 2 - Teste de aceitabilidade da linguiça

Lima et al. (2007) referem que a atitude do consumidor em relação a uma preparação é construída a partir de suas experiências e informações em relação a mesma, influenciando a agir favorável ou desfavoravelmente em relação ao produto.

Portanto não foi detectada diferença significativa $(p<0,05)$ quanto o perfil de atitude dos provadores das duas formulações cujas médias 3,2 e 3,0, respectivamente, para os produtos com bacon e sem bacon evidenciaram boa aceitação dos mesmos, com possibilidade de consumo freqüente (Figura 3). As médias encontradas no presente trabalho é muito próximo aos verificados por Correia et al., 2001.

Os resultados do teste revelam tendência dos provadores a preferirem formulações contendo bacon, o qual apresenta sabor forte e característico dos embutidos tradicionais. A formulação de peixe e bacon revelou-se a preferida.

\section{Perfil de Atitudes}

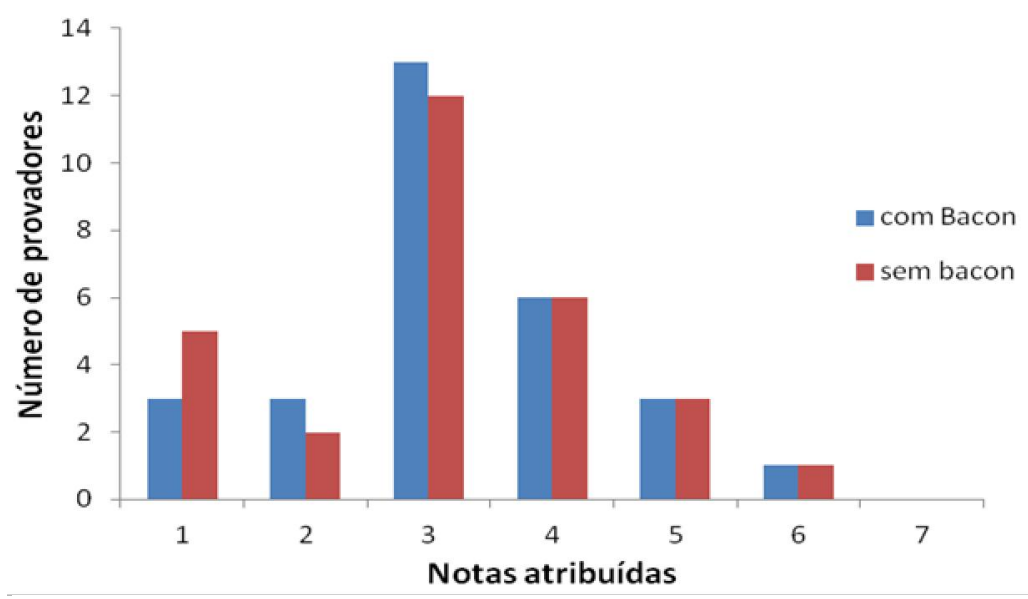

Figura 3 - Teste de preferência da linguiça 
Luciana Façanha Marques et al.

\section{Análises físico-químicas}

Os resultados das análises realizadas na linguiça de peixe estão descritas na tabela 3 .

Tabela 3: Valores encontrados nas análises físico-químicas da linguiça de peixe

\begin{tabular}{l|c|c}
\hline \multirow{2}{*}{ Análises } & \multicolumn{2}{|c}{ Resultados } \\
\cline { 2 - 3 } & Com Bacon & Sem Bacon \\
\hline $\mathrm{pH}$ & 6,11 & 5,81 \\
\hline Acidez & $0,1168 \%$ & $0,0922 \%$ \\
\hline Proteína & $13,8267 \%$ & $10,4862 \%$ \\
\hline Umidade & $78,0363 \%$ & $82,4350 \%$ \\
\hline Cinzas & $1,8284 \%$ & $2,1263 \%$ \\
\hline Lipídios & $13,7442 \%$ & $14,7435 \%$ \\
\hline
\end{tabular}

Não há legislação específica para embutidos de pescado, porém a legislação para linguiças toscanas (cruas) solicita uma quantidade máxima de umidade de $70 \%$, gordura o máximo de $30 \%$ e proteína o mínimo de 12\% (BRASIL, 2000), assim as linguiças de tilápia (Oreochromis niloticus) estão de acordo com o que pede a legislação vigente, uma vez que a carne do pescado tem diferença da carne de suínos tanto no teor de umidade, que segundo as análises realizadas deram fora dos exigidos para linguiça toscana, quanto nos teores de lipídios já que a carne de pescado apresenta uma quantidade baixa comparada a carne de suínos. As mesmas considerações são válidas para o teor de proteínas.

\section{Análises microbiológicas}

Os resultados expressos na Tabela 4 foram obtidos na analise microbiológica de linguiça de tilápia.

Tabela 4 - Resultados das analises microbiológica da linguiça de peixe

\begin{tabular}{l|c|c|c}
\hline \multirow{2}{*}{\multicolumn{1}{c|}{ MICRORGANISMO }} & \multicolumn{2}{c|}{ VALOR ENCONTRADO } & \multirow{2}{*}{ VALOR } \\
\cline { 2 - 3 } & Sem Bacon & Com Bacon & PERMITIDO \\
\hline Salmonella spp. em $\mathbf{2 5 g}$ & AUSENTE & AUSENTE & AUSENTE \\
\hline Staphylococcus aureus $\mathbf{U F C / g}$ & $10^{2}$ & $10^{2}$ & $10^{3}$ \\
\hline Coliformes fecais (NMP/g) & $10^{3}$ & $10^{3}$ & $10^{3}$ \\
\hline Coliformes totais (NMP/g) & $10^{2}$ & $10^{2}$ & - \\
\hline
\end{tabular}


Luciana Façanha Marques et al.

O resultado encontrado contagens de Salmonella, Staphylococcus aureus e Coliformes fecais se apresenta condizentes com os limites previstos pela RDC $\mathrm{n}^{\circ} 12$ do Ministério da Saúde, na qual estipula $10^{3}$ como parâmetro máximo para Staphylococcus aureus e coliformes fecais, para Salmonella ausência (BRASIL, 2001). O resultado mostra que os procedimentos sanitários e higiênicos foram corretamente seguidos desde a captura até a preparação da lingüiça, visto que essa bactéria encontra-se amplamente distribuída no meio ambiente, podendo ser encontra da principalmente, na pele e mucosa nasal do homem (VANZO \& AZEVEDO, 2003). Se fosse confirmada a presenças dos mesmos, a linguiça seria descartada para consumo humano para impedir qualquer tipo de toxinfecções alimentares.

A legislação indica não limites em pescado para o grupo dos coliformes totais, mas é importante analisar a presença deste grupo em alimentos, por estarem diretamente relacionado à qualidade higiênico-sanitária do mesmo. Segundo Agneses et al., (2001) em estudos realizados com filés de pescado, relatou que valores superiores a 106 UFC.g-1 são considerados críticos com relação ao grau de frescor.

\section{Conclusão}

A produção de linguiça de tilápia (Oreochromis niloticus) mostra-se uma alternativa viável para alimentação, no que diz respeito aos quesitos de valor nutritivo $\mathrm{e}$ praticidade, tornando-se uma forma mais fácil do consumo do peixe. Apresentando também um bom índice de aceitação, sendo preferida a formulação com maior teor de lipídeos mostrando uma tendência de consumo maior a partir dos subprodutos do pescado.

Embora o consumo de diferentes tipos de linguiças esteja associado a inúmeros surtos de salmonellose em humanos (GIOVANNINI et al, 2007) por ser um produto suscetível à contaminação e proliferação de microrganismos durante o preparo, manufatura e estoque, este trabalho verificou que a amostra avaliada estava de acordo com os parâmetros preconizados pela legislação.

\section{Referências}

AGNESE, P. A.; OLIVEIRA, M. V.; SILVA, O. P. P; OLIVEIRA, A. G. Contagem de Bactérias Heterotróficas Aeróbias Mesófilas e Enumeração de Coliformes Fecais e Totais, em Peixe Fresco Comercializado no Município de Soropédica RJ. Revista Higiene Alimentar, São Paulo. v. 13 ,n. 88,p. 67 - 70, set. 2001.

BRASIL. Leis, decretos, etc. Lei $\mathrm{n}^{\circ} 1283$, de 18 de dezembro de 1950. Seção 1,p. 74.Pescado e Derivados 1976.

BRASIL. Ministério da Agricultura. Instrução Normativa $\mathrm{n}^{\circ} 4$ de 31 de março de 2000. Regulamento Técnico de Identidade e Qualidade de lingüiça. Diário Oficial [da] República Federativa do Brasil. Poder Executivo, Brasília, 5 de abr. de 2000. Disponível em http://200.252.165.21/sda/dipoar/instnorma4_li nguiÁa3.htm. Acesso em: 15 maio. 2010.

CORREIA, R. T. P.; MENDONÇA, S.C.; LIMA, M.L.; SILVA; P. D. Avaliação química e sensorial de linguiças de pescado tipo frescal. Disponível em:http://ojs.c3sl.ufpr.br/ojs2/index.php/alimen tos/article/viewFile/1232/1032Acesso em:14/junho/2010.

DUTCOSKY, S. D. Análise Sensorial de Alimentos. Curitiba: Champagnat, 1996, $123 \mathrm{p}$.

FAO. Fisheries Global Information System. Disponível em:< http://www.fao.org $>$. Acesso em: 25 de abril de 2010.

FERREIRA, S. O. Aplicação de tecnologias a espécies de pescado de água doce visando atender a agroindústria rural. Piracicaba, p.122,1987.

GIOVANNINI, A.; PRENCIPE, V.; CONTE, 
Luciana Façanha Marques et al.

A.; MARINO, L.; PETRINI, A.; POMILIO, F.; RIZZI, V.; MIGLIORATI, G. Quantative risk assessment of Salmonella spp. infection for the consumer of pork products in an italian region. Food Control, 2007 v.15, p.139-144.

\section{INSTITUTO ADOLFO LUTZ. Normas Analíticas do Instituto Adolfo Luts.V.1:Métodos físico-químicos para analises de Alimentos.IV.Ed.São Paulo:IMESP.2004.}

KIRSCHNIK, P. G. Avaliação da estabilidade de produtos obtidos de carne mecanicamente separada de tilápia nilótica (Oreochromis niloticus).

Disponível em: $<$ http://www.caunesp.unesp.br/Publicacoes/ Dissertacoes Teses/Teses/Tese $\% 20$ Peter\%20G aberz\%20Kirschnik.pdf> Acesso em: 14 de maio 2010 .

LEITÃO, M. F. F. Microbiologia e deterioração do pescado fresco e refrigerado de origem fluvial ou marinha. Santos, SP, Brasil. In: Simpósio sobre Qualidade Microbiológico, Químico, Físico e Organoléptico de pescado e derivados, 28-30 de novembro, 1994. Santos, SP. Anais... p.1126, 1994.

LIMA, A.; SANABRIA, G. G. R.; WHARTA, E. R. S. A.; BEHRENS, J. H.; FILHO, J. M. Avaliação da aceitação de arroz com pequi. Ciências Exatas e da Terra, Ponta Grossa, v.13, n.3, p.45-51, dez. 2007.

MINOZZO, M., G.; VAZ, S., K.; FERRARI, A., P.; MARTINS, C., V., B. Perfil dos Consumidores do Pescado no Município de Toledo/PR. In: SIMPÓSIO BRASILEIRO DE AQÜICULTURA, 12, 2002, Goiânia. Anais (CDROM)... SIMBRAQ, Goiânia/GO, 2002.

SALES, R de O.;OLIVEIRA; J. A. P. de; COSTA, F. J. L.; SALES, A. M. Avaliação de estado do frescor do pescado capturado em água doce e mantido sob refrigeração, no açude de Orós, Ceará. Ciências agronômicas. V:19,p.;109-115,1988

VANZO, S. P.; AZEVEDO, R. V. P. Detecção de S. aureus em manipuladores de alimentosPerfil da resistência a antibiótico e quimioterápicos. Revista Higiene Alimentar, v.17, n.104/105, p. 114-123, 2003.

VAZ, S. k. Elaboração e caracterização de lingüiça fresca tipo "toscana" de Tilápia (Oreochromis niloticus). Disponível em: $<$ http://dspace.c3sl.ufpr.br/dspace/bitstream /handle/1884/2169/Disserta\%E7ao\%20simone \%20vaz.pdf;jsessionid=B7D74359C824F25DD 9403DBA9F7550D3? sequence $=1>\quad$ Acesso em: : 14 de maio de 2010

WEBWER, J. Estabilidade lipídica de filés de Jundiá (Rhamdia quelen). Disponível em: $<$ http://cascavel.cpd.ufsm.br/tede/tde_arquivos/2 2/TDE-2007-10-24T194538Z928/Publico/JUCIELIWEBER.pdf $>$. Acesso em: 12 de maio de 2010. 